\title{
Ethanol-induced DNA damage and repair-related molecules in human intestinal epithelial Caco-2 cells
}

\author{
SUNG CHUL PARK ${ }^{1 *}$, JI-YOUN LIM ${ }^{2 *}$, YOON TAE JEEN ${ }^{3}$, BORA KEUM $^{3}$, YEON SEOK SEO ${ }^{3}$, \\ YONG SIK KIM ${ }^{3}$, SUNG JOON LEE ${ }^{1}$, HONG SIK LEE ${ }^{3}$, HOON JAI CHUN ${ }^{3}$, SOON HO UM ${ }^{3}$, \\ CHANG DUCK KIM ${ }^{3}$, HO SANG RYU ${ }^{3}$, DONGGEUN SUL ${ }^{2}$ and EUNHA OH ${ }^{4}$ \\ ${ }^{1}$ Division of Gastroenterology and Hepatology, Department of Internal Medicine, \\ Kangwon National University School of Medicine, Chuncheon; ${ }^{2}$ Graduate School of Medicine, \\ Korea University; ${ }^{3}$ Division of Gastroenterology and Hepatology, Department of Internal Medicine, \\ Korea University College of Medicine; ${ }^{4}$ Neodin Medical Science Institute, Seoul, Republic of Korea
}

Received October 30, 2011; Accepted January 3, 2012

DOI: $10.3892 / \mathrm{mmr} .2012 .754$

\begin{abstract}
The acute administration of ethanol to intestinal epithelial cells causes increased intestinal permeability and the translocation of endotoxins. The changes caused by ethanol in intestinal cells may be related to oxidative stress and DNA damage. However, DNA damage and repair-related molecules which act against stresses, including ethanol, have not been fully investigated in intestinal cells. Heat shock proteins (Hsps) are involved in the recovery and protection from cell damage and may be associated with DNA repair. Therefore, the aim of our study was to investigate cytotoxicity, DNA damage and the expression of DNA repair-related molecules, antioxidant proteins and Hsps in intestinal cells exposed to ethanol. Human intestinal Caco-2 cells were incubated with 1-8\% ethanol for $1 \mathrm{~h}$. Cell viability and DNA damage were determined using the MTT and comet assays, respectively. We measured DNA repairrelated molecules, including DNA polymerase $\beta$, apurinic/ apyrimidinic endonuclease/redox factor-1 (APE/Ref-1), growth arrest and DNA damage $45 \alpha$ (GADD45 $\alpha$ ) and proliferating cell nuclear antigen (PCNA), in Caco-2 cells using western blot analysis. We also measured glutathione peroxidase-1 (GPx-1), peroxiredoxin-1 (PRX-1), superoxide dismutase-2 (SOD-2), Hsp10, Hsp27, Hsp60, heat shock cognate (Hsc)70, Hsp70 and Hsp90. The viability of the Caco- 2 cells exposed to ethanol decreased at concentrations $\geq 7 \%(\mathrm{P}<0.05)$. The Olive tail moment, indicating DNA damage, increased dose dependently
\end{abstract}

Correspondence to: Dr Yoon Tae Jeen, Division of Gastroenterology and Hepatology, Department of Internal Medicine, Korea University Anam Hospital, Korea University College of Medicine, 126-1, Anam-dong 5 ga, Seongbuk-gu, Seoul 136-705, Republic of Korea

E-mail: ytjeen@korea.ac.kr

*Contributed equally

Key words: Caco-2 cells, DNA repair molecules, heat shock proteins in $\geq 3 \%$ ethanol $(\mathrm{P}<0.05)$. Among the DNA repair proteins, the expression of PCNA and APE/Ref-1 increased significantly at $1 \%$ ethanol. Antioxidant enzymes, including GPX-1, PRX-1 and SOD-2, had an increased expression at 1\% ethanol. Hsp10, Hsp27 and Hsp70 expression also increased significantly at $1 \%$ ethanol. In conclusion, the expression of DNA repair molecules, antioxidants and Hsps increased in intestinal Caco-2 cells exposed to low concentrations of ethanol. In particular, PCNA, APE/Ref-1, Hsp10, Hsp27 and Hsp70 were sensitive to low ethanol concentrations, indicating that they may be useful in evaluating the DNA repair and cytoprotective effects of the drug against stress in intestinal cells.

\section{Introduction}

The acute administration of ethanol to intestinal epithelial cells causes increased intestinal permeability and the translocation of endotoxin, which is a component of the outer wall of Gram-negative bacteria and is normally excluded by the intestinal barrier. Despite several studies, the pathogenesis of the effects of ethanol on the small intestine is not yet clear (1-3). One study indicated that structural and functional abnormalities caused by ethanol are associated with oxidative stress and this was suggested as the mechanism by which ethanol increases intestinal permeability (4). This model has recently been demonstrated in lung cells (5). Increases in reactive oxygen species (ROS) by oxidative stress increase lipid, protein and DNA peroxidation. ROS from xenobiotics, including ethanol, cause oxidative DNA damage through single-strand breaks (6). According to Bradford et al (7), when ethanol is administered to the liver of rats, the expression of DNA repair enzymes increases and may be used as a sensitive DNA damage marker. Interest in the small intestine has been on the increase due to the development of capsule endoscopy and enteroscopy (8). However, only a few studies have been conducted on DNA damage and repair associated with oxidative stress caused by ethanol in the small intestine.

Base excision repair (BER) is the main DNA repair mechanism, which maintains the stability of the genome in 
response to DNA damage caused by reactive chemicals that are constantly created (9). A variety of repair-related enzymes and proteins, including DNA polymerase $\beta$, apurinic/apyrimidinic endonuclease/redox factor-1 (APE/Ref-1), proliferating cell nuclear antigen (PCNA) and growth arrest and DNA damage $45 \alpha$ (GADD45 $\alpha$ ) are used in BER. However, DNA damage and repair-related enzymes in intestinal cells which act against stresses including ethanol have not been fully investigated.

Heat shock proteins (Hsps) are cell proteins that remove or repair denatured proteins and prevent protein aggregation. Hsps are involved in recovery and protection from cell damage. Hsps are associated with DNA repair enzymes and related proteins during cellular oxidative damage $(10,11)$.

Therefore, the aim of our study was to investigate cytotoxicity, DNA damage and the expression of DNA repair-related molecules, antioxidant proteins and Hsps in intestinal cells exposed to ethanol for a short time.

\section{Materials and methods}

Chemicals. Urea, thiourea, 3-[(3-Cholamidopropyl)dimethylammonio]-1-propanesulfonate, dithiothreitol, acrylamide, NN'-methylene-bisacrylamide, tris and sodium dodecyl sulfate (SDS) were purchased from Sigma Chemical (St. Louis, MO, USA). Ethanol was purchased from Merck (Merck Co., Darmstadt, Germany).

Cell culture. Caco- 2 cells, a human colorectal adenocarcinoma cell line, were obtained from American Type Culture Collection (ATCC-HTB-37 ${ }^{\mathrm{TM}}$; Manassas, VA, USA). These cells form polarized monolayers that morphologically and functionally resemble adult human small intestinal mucosal cells subsequent to reaching confluence. Cells were maintained in MEM containing $20 \%$ fetal bovine serum albumin (ATCC), penicillin $(100 \mathrm{U} / \mathrm{ml})$ and streptomycin $(100 \mu \mathrm{g} / \mathrm{ml})$ at $37^{\circ} \mathrm{C}$ in a $5 \% \mathrm{CO}_{2}$ in air atmosphere. Cells cultured for $1 \mathrm{~h}$ with 1, 2, 3, 4, 5, 6, 7 and $8 \%$ ethanol were used for the 3-(4,5-dimethylthiazol-2-yl)2,5-diphenyl tetrazolium bromide (MTT) and comet assays, as well as in western blot analysis.

MTT assay. Caco-2 cells $\left(1 \times 10^{4}\right)$ were incubated with different concentrations $(1,2,3,4,5,6,7$ and $8 \%$ ) of ethanol in 96-well plates for $1 \mathrm{~h}$ and cell viability was determined using the MTT assay (Calbiochem, San Diego, CA, USA) (12). Briefly, $20 \mu \mathrm{l}$ of $5 \mathrm{mg} / \mathrm{ml}$ MTT in phosphate-buffered saline (PBS; Gibco BRL, Paisley, Scotland, UK) was added to each well and incubated for $3 \mathrm{~h}$ at $37^{\circ} \mathrm{C}$. The media were then removed and formazan crystals in the cells were dissolved in the presence of $200 \mu 1$ lysis buffer $(5 \% \mathrm{w} / \mathrm{v}$ of SDS in $0.01 \mathrm{~N} \mathrm{HCl})$. The plates were read at a $590 \mathrm{~nm}$ wavelength using an ELISA reader (Molecular Devices Co., Sunnyvale, CA, USA). The percentage of cell proliferation and cytotoxicity was determined by comparing the optical densities of the cells treated with different concentrations of ethanol with that of the control. Each experiment was repeated seven times.

Comet assay. DNA damage was determined using the comet assay.Thisassay wasperformedaccordingtoSinghetal withminor modifications (13). Briefly, normal and low melting point agarose (NMA and LMA, respectively; Ameresco, Solon, OH, USA) was added to fully frosted slides that were precoated with $50 \mu \mathrm{l}$ $1 \%$ NMA for firm attachment and the slides were then allowed to solidify with cover slips in the refrigerator for $5 \mathrm{~min}$. Following solidification of the gel, the cover slips were removed and $50 \mu \mathrm{l}$ cells mixed with $50 \mu \mathrm{l}$ of $1 \%$ LMA were added. The cover slips were added on to the layer and the slides were allowed to solidify in the refrigerator for $5 \mathrm{~min}$. Following the removal of the cover slips, $100 \mu \mathrm{l}$ of $0.5 \%$ LMA was added as a third layer and the slides were again placed with cover slips in the refrigerator for $5 \mathrm{~min}$. The slides were submersed in a lysing solution (2.5 M NaCl, $100 \mathrm{mM}$ EDTA-2Na, $10 \mathrm{mM}$ Tris- $\mathrm{HCl}$, pH 10; $1 \%$ Triton X-100 and 10\% DMSO, pH 10 added fresh) for $1 \mathrm{~h}$. The slides were then placed in an unwinding buffer (1 mM EDTA and $300 \mathrm{mM} \mathrm{NaOH}, \mathrm{pH}$ 13) for $20 \mathrm{~min}$ and electrophoresis was performed using the same solution for $20 \mathrm{~min}$ at $25 \mathrm{~V}$ and $300 \mathrm{~mA}(0.8 \mathrm{v} / \mathrm{cm})$. Following electrophoresis, the slides were neutralized by washing three times with neutralization buffer (400 mM Tris- $\mathrm{HCl}, \mathrm{pH} 7.4)$ for $5 \mathrm{~min}$ each and were then stained with $50 \mu \mathrm{l}$ of $10 \mu \mathrm{g} / \mathrm{ml}$ ethidium bromide. The slides were examined using a Komet 4.0 image analysis system (Kinetic Imaging, Liverpool, UK) fitted with an Olympus BX50 fluorescence microscope (Olympus, Tokyo, Japan) and equipped with a 515-560 nm excitation filter and a $590 \mathrm{~nm}$ barrier filter. Two slides were prepared for each treatment group and 50 randomly selected cells (total 100 cells) were scored manually. The parameter Olive tail moment [=(Tail.mean-Head.mean) x Tail\%DNA/100] was automatically calculated using the Komet 4.0 image analysis system, which was used for global comet description. Each experiment was repeated three times.

Western blotassay. Caco-2 cells were solubilized in a lysis buffer ( $\mathrm{pH} 7.4$ ) on ice using a homogenizer. The lysates were then clarified by centrifugation at $12,000 \mathrm{rpm}$ for $15 \mathrm{~min}$ at $4^{\circ} \mathrm{C}$ and the protein concentration of the total lysate was determined using a Bradford protein assay (Bio-Rad Laboratories, Richmond, CA, USA). An equal amount of protein per lane was separated by electrophoresis on 8 and 15\% SDS-polyacrylamide gels and then transferred to polyvinylidene difluoride membranes (Millipore Corporation, Bedford, MA, USA) at $400 \mathrm{~mA}$ for $160 \mathrm{~min}$ using a transfer buffer $(\mathrm{pH}$ 8.3). The membranes were blocked with blocking buffer (PBS containing 5\% skimmed milk) for $1 \mathrm{~h}$ at room temperature, followed by incubation with primary antibodies overnight at $4^{\circ} \mathrm{C}$. Subsequent to the membranes being washed three times with PBS-T for $20 \mathrm{~min}$, they were further incubated with horseradish peroxidase-conjugated secondary antibodies [anti-rabbit IgG and anti-mouse IgG (1:2,000; Santa Cruz Biotechnology, Santa Cruz, CA, USA)] for $1 \mathrm{~h}$ at room temperature and washed three times for 20 min with PBS-T. Following extensive washing, the immune complexes were then detected using the enhanced chemiluminescence (ECL) and ECL Plus systems (Amersham Pharmacia Biotech, Piscataway, NJ, USA). Primary antibodies against DNA polymerase $\beta$ (1:1,000; Abcam, Cambridge, MA, USA), APE/Ref-1 (1:4,000; Santa Cruz Biotechnology), PCNA (1:100; Santa Cruz Biotechnology), GADD45 $\alpha$ (1:500; Santa Cruz Biotechnology), glutathione peroxidase-1 (GPx-1; 1:1,000; Abcam), peroxiredoxin-1 (PRX-1; 1:1,000; Santa Cruz Biotechnology), superoxide dismutase-2 (SOD-2; 1:10,000; Abcam), Hsp10 (1:20,000; Abcam), Hsp27 (1:1,000; Cell 


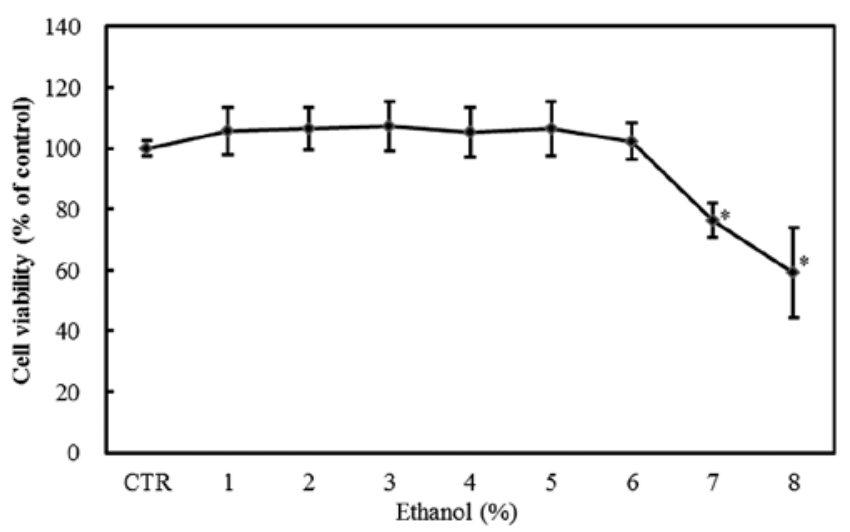

Figure 1. Effect of graded ethanol concentrations (1-8\%) on the viability of Caco- 2 cells as assessed by the MTT assay. Values are mean \pm SD. ${ }^{*} \mathrm{P}<0.05$ versus control.

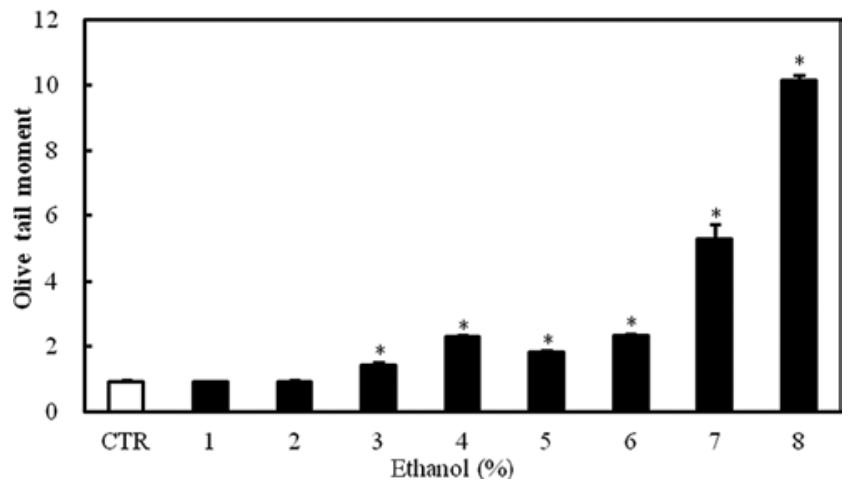

Figure 2. Effect of graded ethanol concentrations (1-8\%) on DNA damage in Caco- 2 cells as assessed by the comet assay. The figure shows the distribution of Olive tail moments, which indicate DNA damage, in Caco-2 cells exposed to ethanol. Values are mean $\pm \mathrm{SD}$. ${ }^{*} \mathrm{P}<0.05$ versus control.

Signaling Technology, Inc., Danvers/Beverly, MA, USA), Hsp60 (1:1,000; Santa Cruz Biotechnology), Hsp70 (1:1,000; Biosciences, San Diego, CA, USA), heat shock cognate (Hsc)70 (1:2,000; Santa Cruz Biotechnology) and Hsp90 (1:4,000; BD Transduction Laboratories) were applied at the optimal concentrations. Bands were visualized by ECL and scanned using a flat-bed scanner. The digitalized images were analyzed using Scion image analysis software (Scion Co., Frederick, MD, USA).

Statistical analysis. Variables were presented as the mean \pm SD and the statistical analysis was performed using an analysis of variance followed by Dunnett's test. $\mathrm{P}<0.05$ was considered to indicate statistically significant results. Data were analyzed using statistical software (SPSS for Windows version 12.0; SPSS Inc., Chicago, IL, USA).

\section{Results}

Cytotoxicity. The exposure of Caco-2 cells to 1-8\% ethanol for $1 \mathrm{~h}$ resulted in a dose-dependent decrease in viability as measured by the MTT assay. The effect was statistically significant at ethanol concentrations $\geq 7 \%$ ( $\mathrm{P}<0.05$; Fig. 1$)$.
$\mathbf{A}$

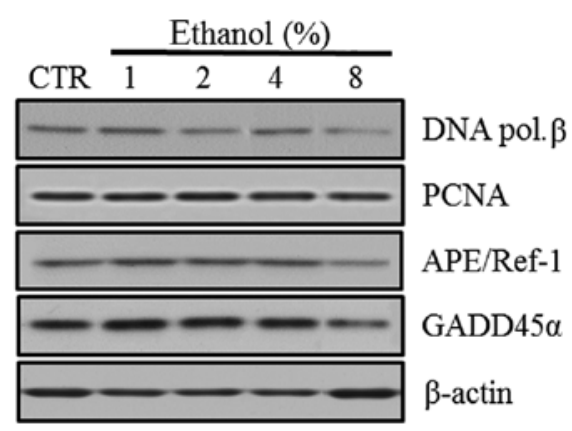

B
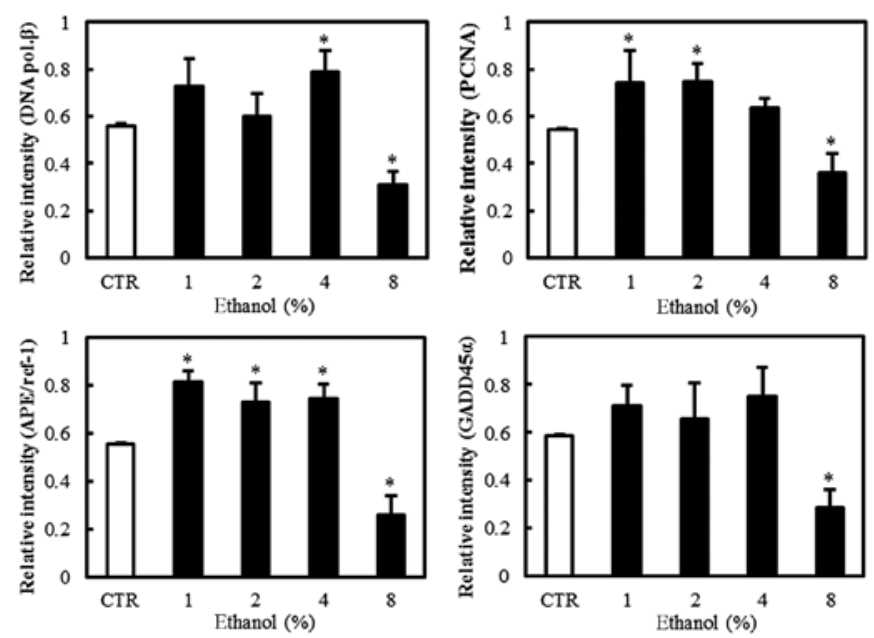

Figure 3. Effect of ethanol on DNA repair enzymes and molecules in Caco-2 cells. (A) Western blot analysis of DNA polymerase $\beta$, PCNA, APE/Ref- 1 and GADD45 $\alpha$. (B) Quantitation of the relative expression intensities of DNA polymerase $\beta$, PCNA, APE/Ref-1 and GADD $45 \alpha$. Values are mean \pm SD ${ }^{*} \mathrm{P}<0.05$ versus control (CTR). PCNA, proliferating cell nuclear antigen; APE/Ref-1, apurinic/apyrimidinic endonuclease/redox factor-1; GADD45 $\alpha$, growth arrest and DNA damage $45 \alpha$; DNA pol. $\beta$, DNA polymerase $\beta$.

DNA damage. The exposure of Caco-2 cells to 1-8\% ethanol for $1 \mathrm{~h}$ caused a dose-dependent increase in the Olive tail moment, which is a DNA damage parameter in the comet assay. The effect was statistically significant at ethanol concentrations $\geq 3 \%$ ( $\mathrm{P}<0.05$; Fig. 2).

Effect of ethanol on DNA repair-related molecules. Western blot analyses were performed to evaluate the expression of the BER pathway DNA repair-related molecules, including DNA polymerase $\beta$, PCNA, APE/Ref- 1 and GADD $45 \alpha$, in Caco-2 cells exposed to graded ethanol concentrations $(1,2$, 4 and $8 \%$ ) for $1 \mathrm{~h}$.

The relative intensities revealed that PCNA and APE/Ref-1 expression increased significantly in Caco-2 cells exposed to $1 \%$ ethanol, the level of DNA polymerase $\beta$ expression increased in 4\% ethanol and GADD45 $\alpha$ expression did not increase significantly in low concentrations of ethanol. The expression of PCNA, APE/Ref-1, DNA polymerase $\beta$ and GADD $45 \alpha$ all decreased at $8 \%$ ethanol (Fig. 3).

Effect of ethanol on antioxidant enzymes. Western blot analyses were performed to evaluate the expression of the antioxidant enzymes GPx-1, PRX-1 and SOD-2 in Caco-2 cells exposed to graded ethanol concentrations $(1,2,4$ and $8 \%$ ) for $1 \mathrm{~h}$. 
A
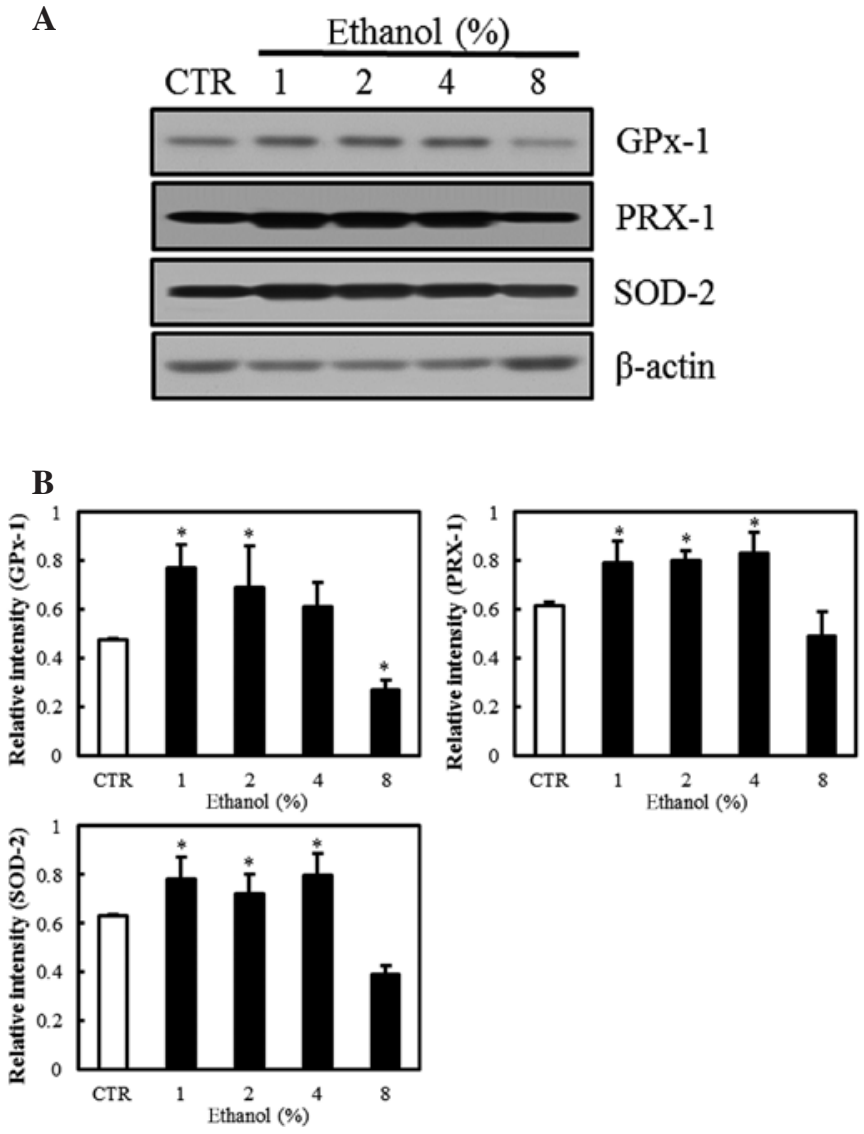

Figure 4. Effect of ethanol on antioxidant enzymes in Caco-2 cells (A) Western blot analysis of GPX-1, PRX-1 and SOD-2. (B) Quantitation of the relative expression intensity of GPx-1, PRX-1 and SOD-2. Values are mean $\pm \mathrm{SD} .{ }^{*} \mathrm{P}<0.05$ versus control (CTR). GPX-1, glutathione peroxidase-1; PRX-1, peroxiredoxin-1; SOD-2, superoxide dismutase-2.

The relative intensities revealed that GPX-1, PRX-1 and SOD-2 expression increased significantly in Caco-2 cells exposed to $1 \%$ ethanol; however, their expression decreased with the $8 \%$ ethanol exposure (Fig. 4).

Effect of ethanol on Hsps. Western blot analyses revealed the level of Hsp expression in Caco-2 cells exposed to graded ethanol concentrations (1,2, 4 and $8 \%$ ) for $1 \mathrm{~h}$. The relative intensities of Hsp10, Hsp27 and Hsp70 expression increased significantly at $1 \%$ ethanol. Hsp10 decreased significantly at $8 \%$ ethanol. Hsp27 and Hsp70 also decreased gradually with further increases in ethanol concentration (Fig. 5).

However, Hsp60 expression increased significantly at a concentration of $4 \%$ ethanol. Hsc70 and Hsp90 expression increased with $2 \%$ ethanol exposure. Hsc70 expression decreased significantly with $8 \%$ ethanol exposure (Fig. 4).

\section{Discussion}

This study examined the cytotoxicity, DNA damage and the expression of DNA repair-related molecules, antioxidants and Hsps in intestinal epithelial cells exposed to low concentrations of ethanol for $1 \mathrm{~h}$.

Acute and chronic exposure of the small intestine to ethanol causes various structural and functional abnormalities. The
A
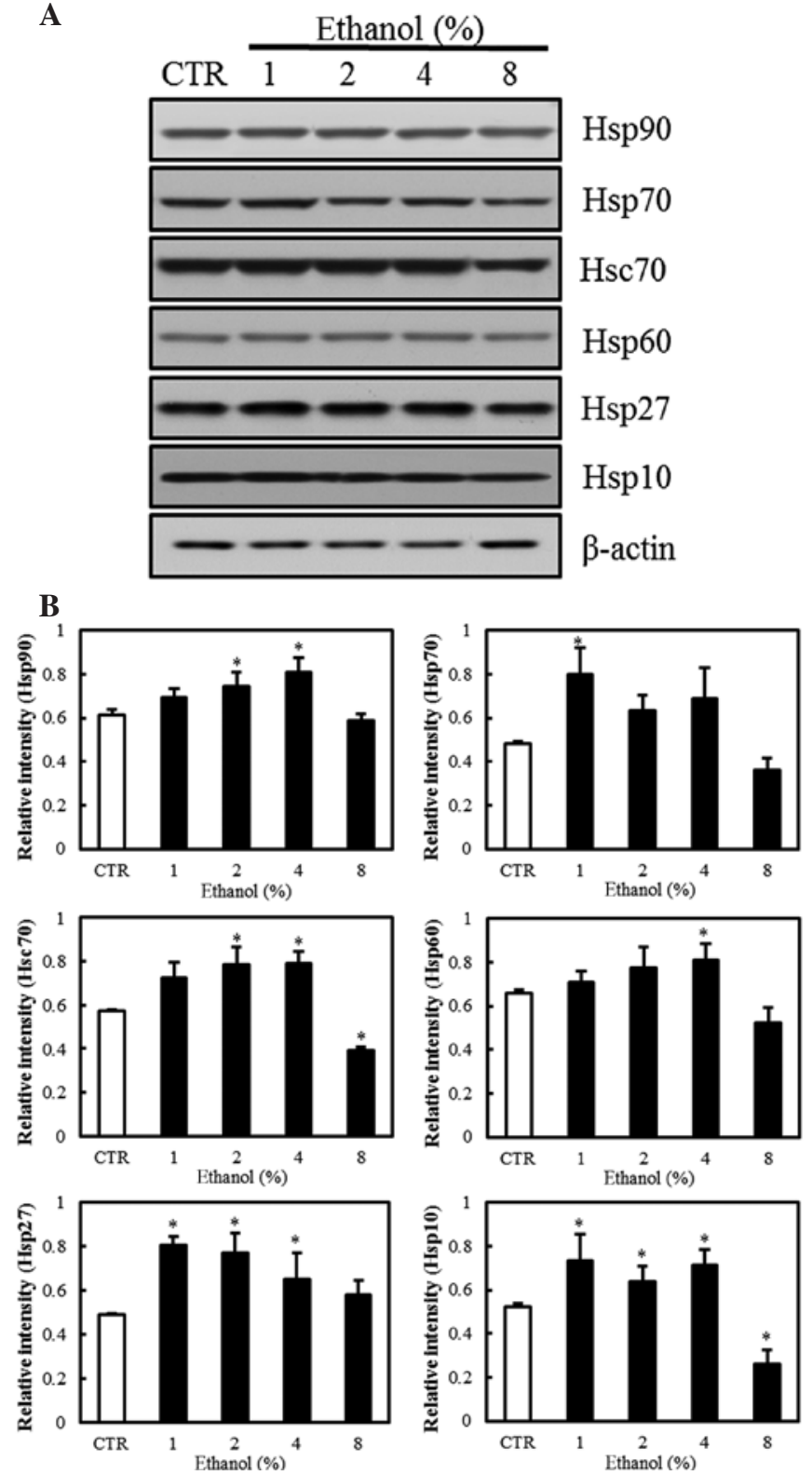

Figure 5. Effect of ethanol on Hsps in Caco-2 cells. (A) Western blot analysis of Hsp10, Hsp27, Hsp60, Hsc70, Hsp70 and Hsp90. (B) Quantitation of the relative expression intensity of Hsp10, Hsp27, Hsp60, Hsc70, Hsp70 and Hsp90. Values are mean \pm SD. ${ }^{*} \mathrm{P}<0.05$ versus control (CTR). Hsp, heat shock protein; Hsc, heat shock cognate.

acute administration of ethanol increases intestinal permeability within $30 \mathrm{~min}$ and causes the transfer of endotoxin into the blood, leading to endotoxemia. Intermittent endotoxemia then stimulates Kupffer cells in the liver and facilitates the formation of ROS and inflammatory mediators, resulting in liver damage.

In our study, 3 and 7\% concentrations of ethanol induced statistically significant DNA damage and cytotoxicity, respectively. Therefore, low ethanol concentrations $(<10 \%)$ may cause intestinal epithelial cell death, as reported in previous studies $(14,15)$. Additionally, genotoxicity may be associated with cytotoxicity. Based on these results, the ethanol concentrations required to observe the expression of proteins and enzymes involved in DNA repair in intestinal epithelial cells 
were determined. Accordingly, Caco-2 cells were exposed to 1 , 2, 4 and $8 \%$ graded ethanol concentrations for $1 \mathrm{~h}$.

The mechanism of BER is as follows (13): DNA glycosylase removes damaged DNA bases by cutting the N-glycosyl bond. The apurinic or apyrimidinic site lacking the DNA base is known as the abasic or the AP site. AP endonuclease (another name for APE/Ref-1) cleaves the phosphodiester backbone near the AP site. DNA polymerase then removes the damaged part of the strand and synthesizes a new strand. Unlike short-patch repair, in which DNA polymerase $\beta$ inserts a single nucleotide, if the AP site is oxidized or reduced, it is resistant to DNA polymerase $\beta$ and long-patch repair occurs. During long-patch repair, DNA polymerases $\delta$ and $\varepsilon$ act with PCNA, which is a repairrelated protein. APE/Ref-1 is a significant indicator of DNA repair enzymes and an essential element in cancer research. GADD $45 \alpha$ is the transcriptional target of p53 and delays carcinogenesis and decreases mutation frequency. A recent study suggested that GADD45 $\alpha$ improves the BER response by binding to DNA and influencing the interaction between cellular APE/Ref-1 and PCNA (16). More research concerning the role of these proteins in DNA damage-repair mechanisms is needed.

In this study, the level of DNA repair-related molecules increased in intestinal epithelial cells exposed to low concentrations of ethanol for a short time. First, PCNA and APE/Ref-1 increased in the $1 \%$ ethanol-exposed cells. DNA polymerase $\beta$ increased at higher concentrations than PCNA and APE/Ref-1. GADD45 $\alpha$ did not show a significant increase. Therefore, PCNA and APE/Ref-1 may be useful in evaluating the level of DNA damage in intestinal epithelial cells. In a previous study, which evaluated DNA damage in human lymphocytes exposed to hydrogen peroxide $\left(\mathrm{H}_{2} \mathrm{O}_{2}\right)$ and methyl methane sulfonate (MMS) for a short time, GADD45 $\alpha$ was more sensitive to DNA damage than other repair-related molecules, including DNA polymerase $\beta$, PCNA and APE/Ref-1 (17). However, different expression patterns of repair-related molecules in Caco- 2 cells compared with lymphocytes were observed in this study. Therefore, although the toxicants used were different, the response to genotoxic compounds may vary according to cell type.

All antioxidant enzymes, including GPx-1, PRX-1 and SOD-2, increased in $1 \%$ ethanol-exposed cells, indicating that oxidative stress is involved in the intestinal cell damage caused by ethanol. Oxidative stress may induce the synthesis of Hsps. Hsps function as molecular chaperones by facilitating protein synthesis, folding, transport, translocation and processing. Hsps are therefore essential for cell survival (5). Hsps are classified into subfamilies depending on their molecular weight, including Hsp60, Hsp70, Hsp90 and the small Hsp family (18).

Among the Hsps, the expression of Hsp10, Hsp27 and Hsp70 increased significantly at $1 \%$ ethanol. Hsc70 and Hsp90 also had significant changes in expression at higher concentrations than those of Hsp10, Hsp27 and Hsp70. Hsp60 also had significant changes in the levels of expression. Different Hsps are induced in different organs. In intestinal epithelial cells, the Hsp70 family and Hsp25 are induced $(19,20)$. Hsp60 has no protective role in the intestine and Hsp10 is a molecular chaperone that functions in protein stabilization and folding with Hsp60 (21). The overexpression of Hsp10 has been reported at a higher rate than Hsp70 in cancer cells, including colorectal cancer (22). It is speculated that Hsp10 affects cell life and death unlike Hsp60, which does not affect cell life and death. In other words, Hsp10 is considered an active factor in the cell signaling pathway and affects the cell cycle, nucleocytoplasmic transport and metabolism (23).

DNA repair-related molecules and Hsps had similar expression patterns based on the ethanol concentration. Their expression intially increased with the increasing ethanol concentration. Expression of most of these molecules significantly changed at an ethanol concentration $<3 \%$, at which point significant DNA damage occurred. However, the expression of all the repair-related molecules decreased at an $8 \%$ ethanol concentration, suggesting that intestinal epithelial cells lose their repair capacity due to cell death, which occurred at a $7 \%$ ethanol concentration in the MTT assay.

It could be inferred that Hsps are associated with DNA repair. Mendez et al (11) revealed that Hsp70 stimulates the BER enzyme, DNA polymerase $\beta$. Kenny et al (10) stated that Hsp70 binds to human AP endonuclease and stimulates endonuclease activity at abasic sites. These studies suggest that a single-strand DNA binding protein may be needed for BER and that Hsps may play a role as BER accessory proteins. If DNA repair-related molecules could be measured according to the induction or suppression of Hsps, they may be useful for clarifying the association between DNA repair and Hsps.

The limitation of our study was the use of a tumor cell line that was not suited to showing physiological phenomena. Although Caco-2 cells originated from human colorectal adenocarcinoma cells, they have similar characteristics to small intestinal epithelial cells. In addition, normal intestinal cell lines, including FHs74Int, are difficult to culture. Therefore, Caco-2 cells were used to investigate the heat shock response and gene expression in this study.

In conclusion, the results revealed that acute and low $(<10 \%)$ concentrations of ethanol induced DNA damage and cytotoxicity in human intestinal epithelial Caco-2 cells. In particular, PCNA, APE/Ref-1, Hsp10, Hsp27 and Hsp70 were more sensitive to ethanol than the other DNA repair molecules and Hsps. These proteins may be useful in evaluating the genotoxicity of toxicants and the DNA repair and cytoprotective effects of drugs in intestinal cells under stress.

\section{References}

1. Bode $\mathrm{C}$ and Bode JC: Effect of alcohol consumption on the gut. Best Pract Res Clin Gastroenterol 17: 575-592, 2003.

2. Bujanda L: The effects of alcohol consumption upon the gastrointestinal tract. Am J Gastroenterol 95: 3374-3382, 2000.

3. Nakagawa K, Adachi J, Wong MCY and Ueno Y: Protective effect of daidzein against acute ethanol-induced lipid peroxidation in rat jejunum. Kobe J Med Sci 52: 141-149, 2006.

4. Farhadi A, Keshavarzian A, Ranjbaran Z, Fields JZ and Banan A: The role of protein kinase $C$ isoforms in modulating injury and repair of the intestinal barrier. J Pharmacol Exp Ther 316: 1-7, 2006.

5. Brown LA, Harris FL, Ping XD and Gauthier TW: Chronic ethanol ingestion and the risk of acute lung injury: a role for glutathione availability? Alcohol 33: 191-197, 2004.

6. Mutlu-Turkoglu U, Dogru-Abbasoglu S, Aykac-Toker G, Mirsal H, Beyazyurek M and Uysal M: Increased lipid and protein oxidation and DNA damage in patients with chronic alcoholism. J Lab Clin Med 136: 287-291, 2000.

7. Bradford BU, Kono H, Isayama F, et al: Cytochrome P450 CYP2E1, but not nicotinamide adenine dinucleotide phosphate oxidase, is required for ethanol-induced oxidative DNA damage in rodent liver. Hepatology 41: 336-344, 2005. 
8. Tennyson CA and Semrad CE: Advances in small bowel imaging. Curr Gastroenterol Rep 13: 408-417, 2011.

9. Christmann M, Tomicic MT, Roos WP and Kaina B: Mechanisms of human DNA repair: an update. Toxicology 193: 3-34, 2003.

10. Kenny MK, Mendez F, Sandigursky M, et al: Heat shock protein 70 binds to human apurinic/apyrimidinic endonuclease and stimulates endonuclease activity at abasic sites. J Biol Chem 276 9532-9536, 2001

11. Mendez F, Kozin E and Bases R: Heat shock protein 70 stimulation of the deoxyribonucleic acid base excision repair enzyme polymerase beta. Cell Stress Chaperones 8: 153-161, 2003.

12. Mosmann T: Rapid colorimetric assay for cellular growth and survival: application to proliferation and cytotoxicity assays. J Immunol Methods 65: 55-63, 1983.

13. Singh NP, McCoy MT, Tice RR and Schneider EL: A simple technique for quantitation of low levels of DNA damage in individual cells. Exp Cell Res 175: 184-191, 1988.

14. Asai K, Buurman WA, Reutelingsperger CP, Schutte B and Kaminishi M: Low concentrations of ethanol induce apoptosis in human intestinal cells. Scand J Gastroenterol 38: 1154-1161, 2003.

15. Ma TY, Nguyen D, Bui V, Nguyen H and Hoa N: Ethanol modulation of intestinal epithelial tight junction barrier. Am J Physiol 276: G965-G974, 1999.

16. Jung HJ, Kim EH, Mun JY, et al: Base excision DNA repair defect in Gadd45a-deficient cells. Oncogene 26: 7517-7525, 2007.

17. Cho EK, Park SY and Sul DG: Comparison of DNA damage and the expression of repair related molecules, including DNA polymerase $\beta, \mathrm{APE} / \mathrm{ref}-1, \mathrm{PCNA}$, and GADD45, in human T and B lymphocytes exposed to hydrogen peroxide and methyl methanesulfonate. In: New Research on DNA Damage. Kimura H and Suzuka A (eds). Nova Science Publishers, Inc., Hauppauge, NY, pp305-318, 2008.
18. Tominaga M, Ohta M, Kai S, Iwaki K, Shibata K and Kitano S: Increased heat-shock protein 90 expression contributes to impaired adaptive cytoprotection in the gastric mucosa of portal hypertensive rats. J Gastroenterol Hepatol 24: 1136-1141, 2009.

19. Otani S, Otaka M, Jin M, et al: Effect of preinduction of heat shock proteins on acetic acid-induced colitis in rats. Dig Dis Sci 42: 833-846, 1997.

20. Ropeleski MJ, Tang J, Walsh-Reitz MM, Musch MW and Chang EB: Interleukin-11-induced heat shock protein 25 confers intestinal epithelial-specific cytoprotection from oxidant stress. Gastroenterology 124: 1358-1368, 2003.

21. Iwabuchi A, Otaka M, Otani S, et al: Specific preinduction of 60-kDa heat shock protein (chaperonin homolog) by TRH does not protect colonic mucosa against acetic acid-induced lesion in rats. Dig Dis Sci 45: 1480-1489, 2000.

22. Junhui C, Liming C, Shaobin W, Jiexiong H, Qiancheng Q and Liyan X: Clinical significance of heat shock protein 10 in large bowel carcinoma. Chinese-German J Clin Oncol 6: 334-338, 2007.

23. Stribinskis V, Heyman HC, Ellis SR, Steffen MC and Martin NC: Rpm2p, a component of yeast mitochondrial RNase P, acts as a transcriptional activator in the nucleus. Mol Cell Biol 25: 6546-6558, 2005. 